\title{
PHYSICAL EDUCATION IN GREAT BRITAIN
}

\author{
By Sir George Newman, G.B.E., K.C.B.
}

$\mathrm{T}^{\mathrm{H}}$ HE debate in the House of Lords on July 12 on the subject of national physical training -introduced by Lord Samuel, discussed in an admirable expository speech by Lord Dawson of Penn, and answered on behalf of the Government by Lord Clifden-has again directed public attention to the urgency of a problem which was first officially raised by the Physical Deterioration Committee of 1904, so long as thirty-six years ago. It will be remembered that that Committee held a grand inquest on the physical condition of the English people, the greatest inquiry of its kind since the Royal Sanitary Commission of 1868: "The people perish for lack of knowledge." It thus set going the action of the State to remedy matters, and recommended the medical inspection and feeding of school children, with the hygiene and physical training of boys, girls and adolescents. Indeed it made fifty-three separate recommendations, some fifty of which have now been adopted or discharged. Their beneficial effects were recognized during the War of 1914-18 by the Ministry of National Service and its Galloway Report on the physical examination of recruits in 1917-18. Now the War recalls us once more to tackle the same old problem.

From the beginning we must be clear about this problem. It finds its source in the advance of medical science, and its solution in social organization and its wise administration. First, as to its science. When Harvey demonstrated the circulation of the blood in 1616, he opened the door to an intelligible understanding of the physiological mechanism of man's body and the purpose of the blood. We now know that "the blood is the life" because it carries food, oxygen and hormones to all parts of the body, and we know also that its circulation is regulated and controlled by the operations, central and peripheral, of the nervous and muscular systems. "Through the motion of the blood," said Harvey in his famous ninth chapter, "the various parts of the body are nourished, cherished, and quickened by the warmer, more perfect, alimentive blood, which discharging its functions quickens the whole body and is indeed the foundation of life and the source of all action." Thus the first purpose of bodily exercise, whether formal or informal, whether of voluntary or involuntary muscle, is the attainment and maintenance of the growth and strength of the body structure as a whole and of its several parts. Secondly, by physical exercise we increase and develop the physiological functioning and nervous regulation of the various organs of the body, to produce a single harmony and a constant balance.

We know by experience that the living body requires food, fresh air (oxygen), warmth, muscular exercise of all its parts, and periodic rest. This has been proved to be the way, and the only way, to health and wholeness; even to survival. The heart is a muscle, the blood vessels have muscular walls, breathing is controlled by muscles, and likewise the digestive system, and thus the body becomes the power-house as well as the muscular engine of living; if we are to live, all these functions must be kept in health and vigour, in tone, readiness and quality by full and continuous stimulation. Finally, exercise keeps the body and mind one single total unity. Though its primary purpose is physical, the culture of the material body and its harmony and control, it is a means of discipline of the mind and spirit of man, to make the body its obedient instrument. Banish the exercise of heart and body and you banish life.

The practice of a regimen of voluntary exercise led the Greeks to devise systems of exercise, followed long afterwards in our own day by Swedish, German, Czech and British methods and physical philosophies. It is a feature common to them all that their social objective was scarcely less than their physical. Their greater end was health and human development, something religious, political, defensive, national, educational. This is strange but true, both in a historical and philosophical sense. Their purpose, expanding beyond the physical realm, thus became infinitely larger than merely the making of athletes or gymnasts. It was to induce manliness, to make and discipline men, to obtain a ready and perfect obedience, as Plato taught, "mainly for the sake of the soul".

Such being the basic science of physical education, there grew up, as civilization advanced, an ever-widening social purpose in its application. It is instructive to note that such purpose became the primary objective of the official recommendations of the Committee of 1904 and of the Ministry of National Service in 1919. Both of them saw poor physique, prevalent disease and high mortality, and they advocated hygiene and physical exercise as preventives; they saw unnecessary industrial 
fatigue in the factories delaying and reducing output, and crying for relief; they saw an urgent necessity for healthier and stronger recruits; they saw a 'half-baked' academic system of education of mind separate from body-and they both found, unanimously, that in disciplined physical education conjoined with the practice of hygiene there was a sovereign remedy, a true method both of healing and of health. Both knew that this was the task and duty of statecraft, and to its application we must now turn.

Nothing in the nature of organized physical education existed prior to 1861, when the army authorities began the physical training of recruits. It was a wooden and rather perfunctory plan of 'setting-up' exercises with dumb-bells and rifles, later amended by an infiltration of Swedish exercise. In 1871, the Education Code (following the Education Act, 1870) introduced school drill, as a meagre and half-hearted recognition of the need for physical training, following the so-called 'model' of the Army. In 1907, when the Board of Education embarked upon the medical supervision of school children, the whole subject was fully and officially explored, and in 1909 a scientific and comprehensive syllabus of instruction was issued by the Board, and physical education became for the first time an essential and integral part of the elementary school curriculum. This has developed into a complete system, with physical training organizers and trained teachers, comprising every kind of exercise, games, dancing, swimming, etc., for the elementary, secondary, technical, continuation schools and evening classes. The effect became almost magical and swept joyously through England, and, in association with medical inspection, hygiene, open-air schools, and school meals has revolutionized the health and physique of the children and young people. A comparison of the physical condition of the school children to-day with that of thirty years ago is patent, arresting and obvious to everybody.

This then is the enduring foundation of national physical education. But it does not yet continue after school days. The extremely precious ageperiod of adolescence has, with two exceptions, been neglected. For the army, navy, and air forces an excellent professional physical training has been available, and for the growing boy and girl Baden-Powell's scout movement came to the rescue, a voluntary movement which has inspired and revitalized the education of youth. Those two exceptions have saved the situation, for they have exerted an indirect effect upon the health education of the nation beyond compute. Concurrently, there has been for a long time past an enormous expansion of voluntary associations for games and sports of all kinds. Thus we have in
England $(a)$ the physical education of all school children, $(b)$ professional physical training for the national services, and $(c)$ a vast congeries of voluntary and varied agencies of leisure-time physical training following the free will and predilection of the individual. That is the three-fold scope of the English position. It is good, but not good enough.

Compare it with the modern German system under the Third Reich and its limitations are apparent : it is not universal, not a compulsory imposition, not for all classes and conditions, not one vast national practice which changes and unifies the character, purpose and aim of a whole people. Yet though the German system has produced a remarkable generation of vigorous and purposive youth, the English people have no desire to imitate it. For its dangers exceed its merits owing to one grave and universal defect: it ignores the individual education, growth, capacity and development of the personality, it is mechanical and 'dragooning', it is subversive of individual freedom and suppressive of national liberty, it is misdirective in purpose and ideal, for it seems to be designed solely to invent and retain a machinemade man for military service, and thus it becomes soul-destroying.

What then should we do? There are three things to do forthwith. First, we must be vigilant to maintain and make absolutely efficient our school system of a broadly conceived and wisely administered system of physical education in every school area of Great Britain; even in these difficult days of evacuation and disturbance of school education. Every child in the country, rich and poor, should receive thorough training in the practice of health and physical exercise, at the hands of competent teachers. Secondly, this inestimable ad vantage should be carried on through adolescence, by means of some form of continuation school or otherwise. Thirdly, the voluntary movements in physical education should be warmly encouraged, organized and co-ordinated by one central body. Fortunately, such an organization already exists, and has abundantly justified itself - the Central Council of Recreative Physical Education (58 Victoria Street, London, S.W.1). This Council is fully representative of all forms of physical training, games and sport. It has done quite invaluable pioneer work in education and demonstration in all parts of the country. It should receive sufficient financial support from the State and the local authorities to make it a still more effective instrument. What the nation needs in this problem is not more inquiries, new bodies or departments, but more united effort, power and imagination to devise ways of cooperating and utilizing the existing means and agencies. 